\title{
Response to the letter to the Editor (Dr Jan Clement et al)
}

\author{
C. Strady • L. Andreoletti
}

Published online: 7 November 2009

(C) Springer-Verlag 2009

Essentially, we are in agreement with the comment provided by Clement et al concerning the Puumala virus reference strain for Hantavirus serodiagnosis in France.

From 1995 to 2000, the French strain denomination IPH 90-13 has been used. Since 2001 the French National Reference Laboratory Centre for Viral Haemorrhagic Fevers (Institut Pasteur Lyon, France) used the correct strain denomination CG 13891 as recommended by Dr J.Clement et al.

In conclusion, despite this problematic choice of Puumala strain in ELISA assay, our results presented in this journal are clinically valuable. We agree that from now onwards the strain character IPH 90-13 should be banned and replaced by the correct name CG 13891.

C. Strady $(\bowtie) \cdot$ L. Andreoletti

Service de Médecine Interne et Des Maladies Infectieuses,

Hôpital Robert Debré-CHU Reims,

Avenue du général Koenig,

51093 Reims Cedex, France

e-mail: cstrady@chu-reims.fr 